\title{
Differences in Lifestyle-related Risk Factors for Death by Occupational Groups; A Prospective Study
}

\author{
Megumi Hara, Mitsuru Mori and Masahiro Nishizumi \\ Department of Community Health Science, Saga Medical School
}

\begin{abstract}
Differences in Lifestyle-related Risk Factors for Death by Occupational Groups; A Prospective Study: Megumi HarA et al. Department of Community Health Science, Saga Medical School-To evaluate the relationship between lifestyle and risk of death from all causes in different occupational groups, we conducted a follow-up (13.6 years) study of 2,262 subjects who were selected randomly out of 40-69 year-old inhabitants of Saga Prefecture in 1983. At that time it was found that among male white-collar workers, as well as blue-collar workers, the risk of death was significantly associated with poor health status. The smoking habit had increased the relative risk of death, but a significant difference was found only among male white-collar workers. Among male farmers, as well as the male blue-collar workers, risk of death was associated with a low score in the physical function test in 1983. In female sales and service workers, the risk of death was significantly associated with decreased physical activity. Among the female farmers, there was no significant relationship between any lifestyle and risk of death. Among the female housekeepers and the retired, the risk of death was significantly associated with poor health status in 1983. Consequently the results of this study suggest that there may be some differences in risk factors for death associated with occupational group, but it can be inferred from the results that keeping in good health, maintaining high physical function, and quitting smoking may reduce the risk of death in all occupational groups.

(J Occup Health 1999; 41: 137-143)
\end{abstract}

Key words: Occupational group, Lifestyle, Health, Mortality, Physical activity

The occurrence of cancer, cardiovascular diseases, and cerebrovascular disorders, which are the main causes of

Received Dec 4, 1998; Accepted Mar 30, 1999

Correspondence to: M. Hara, Department of Community Health Science, Saga Medical School, 5-1-1 Nabeshima, Saga, 849-8501, Japan death in Japan, have been suggested to be related to lifestyle. To establish a means for preventing these diseases, it is important to identify the risk factors in lifestyle for developing them. It has also been mentioned that socio-economic factors play an important role in the incidence and mortality of many diseases. Furthermore, it has been shown that, among socio-economic factors, occupation caused inequality in the rates of survival'). Because there might be some differences in lifestyle among occupational groups, the risk factors for developing these diseases are also thought to differ according to occupation. In this study, we evaluated the relationship between some lifestyles and the risk of death from all causes in several occupational groups in Saga Prefecture.

\section{Subjects and Methods}

As previously reported ${ }^{2}$, personal data were obtained from a survey on lifestyle by means of the uniform questionnaire that had been conducted from October through November of 1983. Briefly, the survey was conducted on 4,010 subjects aged 20 to 69 , randomly selected from all areas of Saga Prefecture in Japan. The questionnaire included inquiries regarding health status, previous diseases, management of health, habitual lifestyle, physical function based on daily living, and personality. From May through July of 1997, we conducted a follow up study by mail on 2,262 subjects (1,152 males and 1,110 females) who were $40-69 \mathrm{yr}$ old in 1983. We received 1,543 returns for 762 males and 781 females, including 109 who had died. We ascertained whether 680 subjects among the other 719 subjects were alive, dead or lost to follow-up (moved away), with the help of the bureau of municipalities and the Cancer Registration office of Saga Prefecture. Altogether we found 327 deaths $(14.5 \%)$ in this study.

The study subjects were classified into 6 occupational groups according to the baseline data. These were whitecollar workers ( 214 males and 84 females), engineers or semi-professional workers (135 males and 31 females), 
Table 1. Number and percentage distributions of subjects according to age strata by sex and occupational group

\begin{tabular}{|c|c|c|c|c|c|c|c|}
\hline \multicolumn{8}{|c|}{ Males } \\
\hline & & \multicolumn{2}{|c|}{ Farmers } & \multicolumn{2}{|c|}{ Blue-collar workers } & \multicolumn{2}{|c|}{ White-collar workers } \\
\hline \multirow[t]{4}{*}{ Age } & $40-49$ & 67 & $23.0 \%$ & 111 & $48.3 \%$ & 110 & $51.4 \%$ \\
\hline & $50-59$ & 102 & $35.1 \%$ & 80 & $34.8 \%$ & 83 & $38.8 \%$ \\
\hline & $60-69$ & 122 & $41.9 \%$ & 39 & $17.0 \%$ & 21 & $9.8 \%$ \\
\hline & total & 291 & $100.0 \%$ & 230 & $100.0 \%$ & 214 & $100.0 \%$ \\
\hline \multicolumn{8}{|c|}{ Females } \\
\hline & & \multicolumn{2}{|c|}{ Housekeepers and the retired } & \multicolumn{2}{|c|}{ Farmers } & \multicolumn{2}{|c|}{ Sales and service workers } \\
\hline \multirow[t]{4}{*}{ Age } & $40-49$ & 117 & $26.0 \%$ & 89 & $32.2 \%$ & 68 & $40.7 \%$ \\
\hline & $50-59$ & 132 & $29.3 \%$ & 108 & $39.1 \%$ & 59 & $35.3 \%$ \\
\hline & $60-69$ & 201 & $44.7 \%$ & 79 & $28.6 \%$ & 40 & $24.0 \%$ \\
\hline & total & 450 & $100.0 \%$ & 276 & $100.0 \%$ & 167 & $100.0 \%$ \\
\hline
\end{tabular}

sales and service workers (115 males and 167 females), farmers (291 males and 276 females), blue-collar workers (230 males and 99 females) and housekeepers or the retired (167 males and 450 females). For further analysis, we selected 3 occupational groups for each gender which were frequently observed. That is, we generally selected male farmers, blue-collar workers and white collar workers and female housekeepers and the retired, farmers, and sales and service workers.

At first, we calculated the standardized mortality ratio (SMR) by occupation ${ }^{3,4)}$. The entire Japanese population in $1990^{5}$, the mid-year of the follow-up period, was used for the standard group. Similarly to what was reported elsewhere ${ }^{2)}$, the lifestyle-related factors adopted were as follows: health status, hours of sleep, taking breakfast, regularity of meals, alcohol consumption, habitual smoking, physical activity, scores of physical function test based on daily living, and body mass index (body weight $(\mathrm{kg})$ /body height $(\mathrm{m})^{2}$, BMI). Scores of physical function were measured by 10 items related to daily living movement, that is: 1) memory of dance or exercise; 2) reflex movement; 3) going up stairs; 4) one-leg standing balance with eyes closed; 5) jumping; 6) flexibility; 7) power of abdominal muscles; 8) power of leg muscles; 9) squatting and returning to a standing position; 10) lifting. Each item was estimated on a grade from 1 to 3 . The highest grade was three points, and the lowest grade was one point. The score for the physical function test was the sum of points. The prevalence rates for having the above 9 lifestyle-related factors were compared among the different occupational groups by a chi-square test. We did not use the person-years method for the analysis, but instead used the logistic regression mode $1^{6)}$ to estimate the age-adjusted relative risks (R.R) and their
95\% confidence intervals (95\%CIs) of lifestyle-related factors for death. The dependent variable was dead or alive status, and the independent variables were each risk factor and age for the logistic regression analysis. We used the SAS system ${ }^{\text {) }}$ for the analysis. The SAS program provided the values for relative risk in the logistic regression analysis.

\section{Results}

Numbers and percentage distributions of the subjects according to age strata by sex and occupational groups are shown in Table 1. Farmers made up the largest proportion in males aged 60 to 69 , and the proportions of white-collar workers and of blue-collar workers were equally large in the males aged 40 to 49 . The proportion of sales and service workers was relatively large in females aged 40 to 49 , although the proportion of housekeepers and the retired was clearly dominant in females.

The present status of the subjects by sex and occupational group is shown in Table 2. Among males, the proportion of dead subjects was largest in farmers, and smallest in white-collar workers, but in females there was no significant difference in the proportion of dead subjects among the 3 occupational groups.

Table 3 shows the age-adjusted SMRs and their 95\% confidence intervals (95\%CIs) for all causes and main causes of death such as cancer, heart disease, cerebrovascular disease, pulmonary disease, chronic hepatitis, accidents and suicide. There were no significant differences from the standard population in terms of the SMRs for all causes and these specific diseases among occupational groups, but it is worth noting the characteristics of these SMRs according to occupational group. Except for male blue-collar workers, the SMRs 
Table 2. Status of the subjects according to gender and occupational group

\begin{tabular}{lrrrrrr}
\hline & \multicolumn{7}{c}{ Males } \\
& \multicolumn{1}{c}{ Farmers } & \multicolumn{2}{c}{ Blue-collar workers } & White-collar workers \\
\hline Alive & 220 & $75.6 \%$ & 179 & $77.8 \%$ & 173 & $80.8 \%$ \\
Dead & 70 & $24.1 \%$ & 41 & $17.8 \%$ & 25 & $11.7 \%$ \\
Moved & 0 & $0.0 \%$ & 6 & $2.6 \%$ & 10 & $4.7 \%$ \\
Unknown & 1 & $0.3 \%$ & 4 & $1.7 \%$ & 6 & $2.8 \%$ \\
\hline Total & 291 & $100.0 \%$ & 230 & $100.0 \%$ & 214 & $100.0 \%$ \\
\hline & & \multicolumn{7}{c}{ Females } & & & \\
& Housekeepers and the retired & Farmers & Sales and service workers \\
\hline Alive & 381 & $84.7 \%$ & 253 & $91.7 \%$ & 149 & $89.2 \%$ \\
Dead & 41 & $9.1 \%$ & 20 & $7.2 \%$ & 10 & $6.0 \%$ \\
Moved & 18 & $4.0 \%$ & 3 & $1.1 \%$ & 6 & $3.6 \%$ \\
Unknown & 10 & $2.2 \%$ & 0 & $0.0 \%$ & 2 & $1.2 \%$ \\
\hline Total & 450 & $100.0 \%$ & 276 & $100.0 \%$ & 167 & $100.0 \%$ \\
\hline
\end{tabular}

Table 3. Age-adjusted proportional mortality ratios (SMRs) by all causes of death according to gender and occupational group

\begin{tabular}{|c|c|c|c|c|c|c|c|c|c|}
\hline \multicolumn{10}{|c|}{ Males } \\
\hline & \multicolumn{3}{|c|}{ Farmers } & \multicolumn{3}{|c|}{ Blue-collar workers } & \multicolumn{3}{|c|}{ White-collar workers } \\
\hline & Death* & SMR & $95 \% \mathrm{CI}$ & Death* & SMR & $95 \% \mathrm{CI}$ & Death* & SMR & $95 \% \mathrm{CI}$ \\
\hline All causes & 70 & 0.92 & $(0.72-1.15)$ & 41 & 1.10 & $(0.79 \cdots 1.47)$ & 25 & 0.83 & $(0.54-1.19)$ \\
\hline Cancers & 34 & 1.25 & $(0.87-1.71)$ & 20 & 1.41 & $(0.86-2.10)$ & 18 & 1.52 & $(0.90-2.30)$ \\
\hline Heart diseases & 4 & 0.57 & $(0.15-1.26)$ & 3 & 0.93 & $(0.18-2.29)$ & 3 & 1.19 & $(0.22-2.91)$ \\
\hline Cerebrovascular disease & 0 & - & - & 7 & 1.58 & $(0.63-2.97)$ & 0 & - & 一 \\
\hline Pulmonary disease & 5 & 0.84 & $(0.26-1.74)$ & 2 & 0.90 & $(0.09-2.59)$ & 0 & - & - \\
\hline Chronic hepatitis & 2 & 0.99 & $(0.09-2.85)$ & 0 & - & - & 0 & - & - \\
\hline Accidents & 5 & 2.01 & $(0.64-4.17)$ & 2 & 1.32 & $(0.12-3.78)$ & 0 & - & - \\
\hline Suicides & 2 & 1.50 & $(0.14-4.31)$ & 0 & 一 & - & 0 & - & - \\
\hline \multicolumn{10}{|c|}{ Females } \\
\hline & \multicolumn{3}{|c|}{ Housekeepers and the retired } & \multicolumn{3}{|c|}{ Farmers } & \multicolumn{3}{|c|}{ Sales and service workers } \\
\hline & Death* & SMR & $95 \% \mathrm{CI}$ & Death* & SMR & $95 \% \mathrm{CI}$ & Death* & SMR & $95 \% \mathrm{CI}$ \\
\hline All causes & 41 & 0.80 & $(0.57-1.06)$ & 20 & 0.72 & $(0.44-1.07)$ & 10 & 0.69 & $(0.33-1.18)$ \\
\hline Cancers & 14 & 0.80 & $(0.43-1.27)$ & 9 & 0.90 & $(0.41-1.59)$ & 8 & 1.51 & $(0.65-2.74)$ \\
\hline Heart diseases & 5 & 0.94 & $(0.30-1.95)$ & 0 & - & - & 0 & - & - \\
\hline Cerebrovascular disease & 4 & 0.51 & $(0.13-1.13)$ & 2 & 0.49 & $(0.05-1.41)$ & 1 & 0.47 & $(0.00-1.85)$ \\
\hline Pulmonary disease & 1 & 0.37 & $(0.00-1.44)$ & 2 & 1.50 & $(0.14-4.30)$ & 1 & 1.48 & $(0.00-5.79)$ \\
\hline Chronic hepatitis & 2 & 1.63 & $(0.15-4.68)$ & 1 & 1.44 & $(0.00-5.65)$ & 0 & - & - \\
\hline Accidents & 0 & - & - & 0 & - & - & 0 & - & - \\
\hline Suicides & 0 & - & - & 1 & 1.34 & $(0.00-5.26)$ & 0 & - & - \\
\hline
\end{tabular}

*: Observed number of deaths. - : could not be calculated. $95 \% \mathrm{CI}$ : 95\% confidence interval of SMR.

for all causes were below 1.0 among all of the occupational groups. Except for female housekeepers and the retired and farmers, the SMRs for cancer were above 1.0. The SMRs for accidents were high among the male farmers and blue-collar workers.

The percentage distribution according to category in each lifestyle-related factor by sex and occupational group is shown in Table 4. In males, a significantly larger 
Table 4. Distribution of levels of lifestyle-related factors according to gender and occupational group

\begin{tabular}{|c|c|c|c|c|c|c|c|c|c|c|c|c|}
\hline & \multicolumn{6}{|c|}{ Males } & \multicolumn{6}{|c|}{ Females } \\
\hline & \multicolumn{2}{|c|}{ Farmers } & \multicolumn{2}{|c|}{$\begin{array}{c}\text { Blue-collar } \\
\text { workers }\end{array}$} & \multicolumn{2}{|c|}{$\begin{array}{c}\text { White-collar } \\
\text { workers }\end{array}$} & \multicolumn{2}{|c|}{$\begin{array}{l}\text { Housekeeper } \\
\text { and the retired }\end{array}$} & \multicolumn{2}{|c|}{ Farmers } & \multicolumn{2}{|c|}{$\begin{array}{c}\text { Sales and } \\
\text { service workers }\end{array}$} \\
\hline & No & $\%$ & No & $\%$ & No & $\%$ & No & $\%$ & No & $\%$ & No & $\%$ \\
\hline \multicolumn{13}{|l|}{ Health status } \\
\hline Almost perfectly healthy & 199 & 68.4 & 153 & 66.5 & 138 & 64.5 & 249 & 55.3 & 190 & $68.8 *$ & 96 & 57.5 \\
\hline Slightly unhealthy & 33 & 11.3 & 24 & 10.4 & 26 & 12.1 & 48 & 10.7 & 29 & 10.5 & 18 & 10.8 \\
\hline Moderately unhealthy & 40 & 13.7 & 36 & 15.7 & 30 & 14.0 & 103 & 22.9 & 42 & 15.2 & 48 & 28.7 \\
\hline Attending a hospital & 19 & 6.5 & 17 & 7.4 & 19 & 8.9 & 50 & 11.1 & 15 & 5.4 & 5 & 3.0 \\
\hline \multicolumn{13}{|l|}{ Hours of sleep } \\
\hline Below 6 hours & 28 & 9.6 & 36 & 15.7 & 20 & 9.3 & 62 & 13.8 & 26 & 9.4 & 28 & $16.8 *$ \\
\hline About 7 hours & 95 & 32.6 & 76 & 33.0 & 107 & 50.0 & 207 & 46.0 & 131 & 47.5 & 99 & 59.3 \\
\hline About 8 hours & 128 & 44.0 & 99 & 43.0 & 71 & 33.2 & 150 & 33.3 & 104 & 37.7 & 38 & 22.8 \\
\hline Over 9 hours & 40 & $13.7 *$ & 19 & 8.3 & 16 & 7.5 & 31 & 6.9 & 15 & 5.4 & 2 & 1.2 \\
\hline \multicolumn{13}{|l|}{ Takes breakfast } \\
\hline Rarely & 24 & 8.2 & 20 & 8.7 & 13 & 6.1 & 35 & 7.8 & 25 & 9.1 & 24 & $14.4^{*}$ \\
\hline Sometimes & 5 & 1.7 & 23 & 10.0 & 29 & 13.6 & 39 & 8.7 & 9 & 3.3 & 24 & 14.4 \\
\hline Every morning & 262 & $90.0 *$ & 187 & 81.3 & 172 & 80.4 & 376 & 83.6 & 242 & 87.7 & 119 & 71.3 \\
\hline \multicolumn{13}{|l|}{ Regularity of meals } \\
\hline Regular & 243 & 83.5 & 159 & 69.1 & 146 & 68.2 & 378 & 84.0 & 243 & 88.0 & 103 & 61.7 \\
\hline Sometimes irregular & 35 & 12.0 & 46 & 20.0 & 57 & 26.6 & 62 & 13.8 & 23 & 8.3 & 47 & 28.1 \\
\hline Irregular & 13 & 4.5 & 25 & $10.9 *$ & 11 & 5.1 & 10 & 2.2 & 0 & 0.0 & 17 & $10.2 *$ \\
\hline \multicolumn{13}{|l|}{ Alcohol consumption } \\
\hline Rarely & 65 & 22.3 & 43 & 18.7 & 46 & 21.5 & 394 & 87.6 & 241 & 87.3 & 122 & 73.1 \\
\hline Sometimes & 72 & 24.7 & 64 & 27.8 & 82 & 38.3 & 41 & 9.1 & 26 & 9.4 & 32 & 19.2 \\
\hline 5,6 times per week & 64 & 22.0 & 122 & 53.0 & 86 & 40.2 & 11 & 2.4 & 4 & 1.4 & 12 & $7.2 *$ \\
\hline \multicolumn{13}{|l|}{ Smoking habit } \\
\hline Never & 60 & 20.6 & 37 & 16.1 & 36 & 16.8 & 395 & 87.8 & 257 & 93.1 & 146 & 87.4 \\
\hline Ceased smoking & 66 & 22.7 & 55 & 23.9 & 56 & 26.2 & 11 & 2.4 & 4 & 1.4 & 7 & 4.2 \\
\hline Less than 19 cigarettes per day & 91 & 31.3 & 76 & 33.0 & 57 & 26.6 & 24 & 5.3 & 3 & 1.1 & 9 & 5.4 \\
\hline 20-39 cigarettes per day & 69 & 23.7 & 51 & 22.2 & 61 & 28.5 & 1 & 0.2 & 1 & 0.4 & 1 & 0.6 \\
\hline Over 40 cigarettes per day & 4 & 1.4 & 7 & 3.0 & 3 & 1.4 & 1 & 0.2 & 0 & 0.0 & 0 & 0.0 \\
\hline \multicolumn{13}{|l|}{ Physical activity } \\
\hline Vigorous sports & 13 & 4.5 & 32 & 13.9 & 36 & 16.8 & 13 & 2.9 & 7 & 2.5 & 9 & 5.4 \\
\hline Light intensity activity & 109 & 37.5 & 84 & 36.5 & 100 & 46.7 & 216 & 48.0 & 66 & 23.9 & 76 & 45.5 \\
\hline None & 169 & 58.1 & 114 & 49.6 & 78 & 36.4 & 220 & 48.9 & 202 & $73.2 *$ & 82 & 49.1 \\
\hline \multicolumn{13}{|l|}{ Physical function score } \\
\hline$\leqq 16$ & 22 & 7.6 & 27 & 11.7 & 22 & 10.3 & 172 & 38.27 & 87 & 31.5 & 57 & 34.1 \\
\hline $17-19$ & 60 & 20.6 & 44 & 19.1 & 44 & 20.6 & 123 & 27.3 & * 75 & 27.2 & 46 & 27.5 \\
\hline $20-21$ & 57 & 19.6 & 38 & 16.5 & 39 & 18.2 & 83 & 18.4 & 49 & 17.8 & 22 & 13.2 \\
\hline $22 \leqq$ & 138 & 47.4 & 118 & 51.3 & 106 & 49.5 & 64 & 14.2 & 58 & 21.0 & 42 & 25.1 \\
\hline \multicolumn{13}{|l|}{ BMI } \\
\hline $\mathrm{BMI}<19.8$ & 47 & 16.2 & 43 & 18.7 & 24 & 11.2 & 80 & 17.8 & 51 & 18.5 & 15 & 9.0 \\
\hline $19.8 \leqq \mathrm{BMI}<24.2$ & 180 & 61.9 & 139 & 60.4 & 128 & 59.8 & 256 & 56.9 & 161 & 58.3 & 108 & 64.7 \\
\hline $24.2 \leqq \mathrm{BMI}$ & 64 & 22.0 & 47 & 20.4 & 62 & 29.0 & 116 & 25.8 & 64 & 23.2 & 43 & 25.7 \\
\hline
\end{tabular}

*: significant $(\mathrm{P}<0.01)$ compared with that of other occupational groups in the same sex. 
Table 5. Age-adjusted relative risks (and $95 \%$ confidence intervals) per category lifestyle-related factors for death

\begin{tabular}{|c|c|c|c|c|c|c|}
\hline & \multicolumn{6}{|c|}{ Males } \\
\hline & \multicolumn{2}{|c|}{ Farmers } & \multicolumn{2}{|c|}{ Blue-collar workers } & \multicolumn{2}{|c|}{ White-collar workers } \\
\hline & R.R & $95 \% \mathrm{CI}$ & R.R & $95 \% \mathrm{CI}$ & R.R & $(95 \% \mathrm{CI})$ \\
\hline Health status & 1.23 & $(0.95-1.58)$ & $1.63 * *$ & $(1.19-2.27)$ & $1.63 * *$ & $(1.17-2.30)$ \\
\hline Hours of sleep & 1.16 & $(0.83-1.64)$ & 0.77 & $(0.49-1.20)$ & 0.83 & $(0.47-1.46)$ \\
\hline Taking breakfast & 1.20 & $(0.71-2.26)$ & 0.65 & $(0.38-1.14)$ & 1.89 & $(0.78-7.10)$ \\
\hline Regularity of meals & 1.38 & $(0.75-2.43)$ & 0.91 & $(0.44-1.74)$ & 0.56 & $(0.20-1.27)$ \\
\hline Alcohol consumption & 0.90 & $(0.64-1.27)$ & 1.04 & $(0.66-1.68)$ & 0.96 & $(0.55-1.71)$ \\
\hline Smoking habit & 1.26 & $(0.70-2.26)$ & 1.22 & $(0.57-2.62)$ & $6.73^{* *}$ & $(1.94-23.41)$ \\
\hline Physical activity & 1.21 & $(0.73-2.03)$ & 1.48 & $(0.85-2.70)$ & 1.59 & $(0.84-3.16)$ \\
\hline Physical function score & $0.61 *$ & $(0.46-0.79)$ & $0.65^{*}$ & $(0.46-0.91)$ & 0.83 & $(0.56-1.25)$ \\
\hline BMI & 0.81 & $(0.51-1.29)$ & 0.62 & $(0.34-1.12)$ & 0.80 & $(0.40-1.60)$ \\
\hline
\end{tabular}

\begin{tabular}{|c|c|c|c|c|c|c|}
\hline & \multicolumn{6}{|c|}{ Females } \\
\hline & \multicolumn{2}{|c|}{ Housekeepers and the retired } & \multicolumn{2}{|c|}{ Farmers } & \multicolumn{2}{|c|}{ Sales and service workers } \\
\hline & R.R & $95 \% \mathrm{CI}$ & R.R & $95 \% \mathrm{CI}$ & R.R & $95 \% \mathrm{CI}$ \\
\hline Health status & $1.50 * *$ & $(1.16-1.93)$ & 1.14 & $(0.72-1.73)$ & 0.87 & $(0.42-1.66)$ \\
\hline Hours of sleep & 1.42 & $(0.94-2.16)$ & 1.18 & $(0.64-2.20)$ & 0.63 & $(0.22-1.70)$ \\
\hline Taking breakfast & 1.10 & $(0.66-2.10)$ & 0.82 & $(0.43-1.93)$ & 0.89 & $(0.41-2.29)$ \\
\hline Regularity of meals & 0.32 & $(0.05-1.00)$ & 1.92 & $(0.72-4.30)$ & 1.42 & $(0.52-3.51)$ \\
\hline Alcohol consumption & 0.93 & $(0.30-2.17)$ & 0.49 & $(0.03-2.07)$ & 0.36 & $(0.02-1.55)$ \\
\hline Smoking habit & 1.54 & $(0.43-5.58)$ & & - & & - \\
\hline Physical activity & 1.58 & $(0.87-2.96)$ & 1.09 & $(0.47-2.96)$ & $4.93 *$ & $(1.25-33.34)$ \\
\hline Physical function score & 0.82 & $(0.56-1.16)$ & 1.09 & $(0.70-1.65)$ & 0.84 & $(0.44-1.49)$ \\
\hline BMI & 0.52 & $(0.31-0.86)$ & 0.60 & $(0.29-1.24)$ & 0.77 & $(0.24-2.39)$ \\
\hline
\end{tabular}

R.R: Relative risk per category except for smoking habit. The categories for each lifestyle-related factor are shown in Table 4 . Relative risk for smoking habit was evaluated by comparing current smokers to nonsmokers (never smoked and ex-smokers). *: $\mathrm{P}<0.05,{ }^{* *}: \mathrm{P}<0.01 . \ldots$ : could not be calculated.

proportion of the farmers used to sleep over $9 \mathrm{~h}(\mathrm{P}<0.01)$ and to take breakfast every morning $(\mathrm{P}<0.01)$ compared with that in the other occupational groups. A significantly larger proportion of the blue-collar workers used to take meals at irregular times $(\mathbf{P}<0.01)$. A significantly larger proportion of the white-collar workers used to do vigorous sports or light intensity activities $(\mathrm{P}<0.01)$. Nevertheless, there were no significant differences among the 3 occupational groups regarding alcohol consumption, smoking habit, score of physical function test, or BMI in males.

In females, a significantly larger proportion of the farmers had felt basically healthy $(\mathrm{P}<0.01)$, and had not been very physically active in the past $(\mathrm{P}<0.01)$ compared with subjects in the other occupational groups. A significantly larger proportion of the sales and service workers used to sleep $7 \mathrm{~h}$ or less ( $\mathrm{P}<0.01$ ), used to skip breakfast $(\mathrm{P}<0.01)$, used to eat meals at irregular times $(\mathrm{P}<0.01)$, and used to drink alcoholic beverages frequently $(\mathrm{P}<0.01)$. A significantly larger proportion of the housekeepers and the retired had lower scores in the physical function test $(\mathrm{P}<0.01)$, but there were no significant differences among the 3 occupational groups with regard to the smoking habit or BMI in the females.

Table 5 shows age-adjusted relative risks and their $95 \%$ confidence intervals per category for the lifestyle-related factors for death. The relative risk of the smoking habit was calculated to indicate the risk to current smokers compared to non-smokers (never smoked and exsmokers). Among the male farmers, the risk of death was significantly lower in the subjects who had higher physical function scores in 1983 (R.R. $=0.61, \mathrm{P}<0.01$ ). Among the male blue-collar workers, the risk of death was significantly higher in the subjects who were in poor health in 1983 (R.R.=1.63, P<0.01), but the risk of death was significantly lower in the subjects who had higher physical function scores in 1983 (R.R. $=0.65, \mathrm{P}<0.05$ ). Among the male white-collar workers, the risk of death 
was significantly higher in the subjects who were in poor health in 1983 (R.R. $=1.63, P<0.01$ ), and in those who had the smoking habit in 1983 ( $R . R=6.73, P<0.01$ ).

Among female housekeepers and the retired, the risk of death was significantly higher in the subjects who were in poor health in 1983 (R.R. $=1.50, P<0.01$ ). In the female farmers, there were no significant lifestyle-related factors for death. Among the female sales and service workers, the risk of death was significantly higher in the subjects who did not engage in physical activities in 1983 (R.R.=4.93, P<0.05).

\section{Discussion}

In this study, the SMRs for accidents and suicides among male farmers and the SMRs for accidents among blue-collar workers were high, although the differences were not significant. When we discuss the health of farmers, it is important to attempt to identify factors in the agricultural environment that might contribute to mortality. Farmers sometimes perform many tasks, including machinery and engine repair, welding, painting, carpentry, operation of heavy equipment, truck driving, applying pesticides, and handling grains and livestock. These activities may result in exposure to pesticides, fuels and oils, solvents, engine exhausts, organic and inorganic dusts, metal, fumes, paints, sunlight, electromagnetic radiation, and zoonotic viruses, microbes, and fungi $\mathrm{i}^{\mathrm{x}, 9}$. It is possible that these environmental factors have an influence on health and mortality. The percentage of subjects who had never smoked was highest in farmers, and among males, farmers had the lowest SMRs from cancer and heart diseases. Furthermore, among male farmers, there was no significant association between the smoking habit and risk of death. On the other hand, the percentage of current smokers was highest in the whitecollar workers, and there was a positive relationship between the smoking habit and risk of death. The smoking habit has been shown to contribute to occupational inequalities in mortality ${ }^{10)}$. Moreover, it has been suggested that a low mortality rate from heart disease or cancers of the lung, esophagus, bladder and colon might be attributable to a lower smoking rate among farmers ${ }^{11-15)}$.

Among male farmers and blue-collar workers, the risk of death was significantly associated with a lower score in physical function in 1983. It has been reported that good dietary and physical activity patterns reduce mortality rate ${ }^{16}$. Other reports have shown that there is an inverse association between the risk of death from all causes and the level of physical fitness ${ }^{17-19}$. It can therefore be considered that maintaining physical function by exercise may reduce the risk of mortality.

Among female sales and service workers, the risk of death was significantly associated with physical activity in 1983. In this study, a significantly larger proportion of the female farmers had not been as physically active as those in the other occupational groups. Nevertheless, in contrast to males, the activity of female farmers still appeared to be greater than that of the other 3 groups, so that the risk of death might be less influenced by physical activity in this group than in sales and service workers. It was possible that the subjects who were more physically active in 1983 might lead more regulated lives, but there were no significant correlations between physical activity, hours of sleep, taking breakfast, regularity of meals, alcohol consumption and smoking habits, although we have not shown the results for these correlations.

Because of the limited sample size in this study, the statistical power was not high enough to detect the small but real difference between the exposed group and the non-exposed group. For example, when the proportions of death in the exposed group and in the non exposed group were 0.20 and 0.05 , respectively, and the alphaerror was 0.05 , the power was calculated to be about 0.70 in our sample size ${ }^{20)}$. The results of this study suggest that there may be some differences in risk factors of death by occupational groups. Because occupational categories and health behavior factors such as hours of sleep, taking breakfast, regularity of meals, overeating, alcohol consumption, the smoking habit, physical activity and stress management might influence each other, further study should help clarify the relationship between each health factor and the risk of death by occupational group. But this study has also indicated that maintaining a good health status, being moderately physically active, having high physical function, and quitting smoking may reduce the risk of death in all occupational groups.

Acknowledgments: We express our gratitude to the staff of cities, towns, and villages in Saga Prefecture for their assistance.

\section{References}

1) Kagamimori $S$, Matsubara I, Sokejima $S$, et al. The comparative study on occupational mortality, 1980 between Japan and Great Britain. Industrial Health 1998; 36: 252-257.

2) Sayanagi $\mathbf{S}$, Uchida $K$, Sueyosi $K$, Kinoshita $T$, Nishizumi $M$. The actual state of health management among inhabitants in Saga Prefecture-A survy by selfadminstered health questionnaire. Koushuueiseijouhou 1985; 15: 26-36 (in Japanese).

3) Charles HH, Julie EB. Epidemiology in medicine. Boston: Little Brown and Company, 1987: 82-85.

4) MacMahon B, Puch TF, Ipsen J. Epidemiologic Methods. Boston: Little Brown and Company, 1960: 207-208.

5) Vital statistics 1990 . Ministry of health and welfare (in Japanese).

6) MacMahon, B, Puch TF, Ipsen J. Epidemiologic Methods. Boston: Little Brown and Company, 1960: 290-291.

7) SAS Institute Inc., SAS Technical Report P-200, SAS/ 
STAT Software: CALIS and LOGISTIC Procedures, Release 6.04, Cray, NC: SAS Institute Inc., 1990: 175230.

8) Donham KJ. Hazardous agents in agricultural dusts and methods of evaluation. Am J Ind Med 1986; 10: 205 220.

9) Dutkiewicz J, Jablonski L, Olenchock SA. Occupational biohazards: A review. Am J Ind Med 1988; 14: 605-623.

10) Pearce NE, Davis PB, Smith AH, et al. Social class, ethnic group, and the male mortality in New Zealand, 1974-8. J Epidemiol Community Health 1985; 39: 915.

11) Blair A, Zahm SH, Pearce N, et al. Clues to cancer etiology from studies of farmers. Scand J Work Environ Health 1992; 18: 209-215.

12) Walrath J, Rogot E, Murray J, Blair A. Mortality patterns among United States veterans by occupation and smoking status. NIH publication No. 85-2756. Washington, DC; National Institutes of Health 1985.

13) McMichael AJ, Hartshorne JM. Mortality risks in Australian men by occupation groups, 1968-1978. Med J Aust 1982; 1: 253-256.
14) Cassel J, Heyden S, Bartel AG, et al. Occupational and physical activity and coronary heart disease. Arch Intern Med 1971; 128: 920-928.

15) Surgeon General. Smoking and health: a report of the Surgeon General. Washington, DC: Office of the Surgeon General, 1971.

16) McGinnis JM. The public health burden of a sedentary life style. Med Sci Sports Exerc 1992; 24: 196-200.

17) James BK, Steven NB, Carolyn EB, et al. Physical activity, physical fitness, and all-cause and cancer mortality: a prospective study on men and women. AEP 1996; 6: 452-457.

18) Blair SN, Kohl HW, Paffenbarger RS, et al. Physical fitness and all-cause mortality: a prospective study of healthy men and women. JAMA 1989; 262: 23952401.

19) Bokovoy JL, Blair SN. Aging and exercise: a health perspective. Journal of Aging and Physical Activity 1994; 2: 243-260.

20) Fliss JL. Statistical Methods for Rates and Proportions, second edition. Canada: John Wiley \& Sons, Inc, 1981: 33-49. 